\title{
USEFULNESS OF MANAGEMENT ACCOUNTING INFORMATION IN DECISION MAKING AMONG SMES: THE MODERATING ROLE OF CLOUD COMPUTING
}

\author{
Ruhanita Maelah ${ }^{*}$, Mohammed Fadhil Farhan Al Lami \\ and Gheyath Ghassan ${ }^{3}$ \\ ${ }^{1}$ Faculty of Economics and Management, \\ Universiti Kebangsaan Malaysia, Malaysia. \\ ${ }^{2}$ Gazprom Company, Iraq. \\ ${ }^{3}$ Warba Company, Iraq.
}

\begin{abstract}
Small and medium sized enterprises (SMEs) are the biggest contributors to the Malaysian economy with more than a third of total gross domestic product (GDP) delivered by these industries. In a competitive business environment, SMEs need to utilize information and technology in making decisions. This study aimed to see the relationship between management accounting information (MAI), decision-making, and cloud computing among SMEs in Malaysia. A quantitative research design utilizing survey questionnaires were used to collect the data. The survey was conducted on 384 Malaysian small and medium-sized enterprises in various sectors. The study obtained 105 useable responses which were analysed using Smart PLS 3.0 (Partial Least Square). The study found all the dimensions of MAI; namely broad scope, timeliness, aggregation and integration, positively related to decision-making. The findings also indicated that cloud computing moderated the relationship between MAI and decision-making. The results provided evidence for organizations to realize the importance of MAI, and strategize how to relate to information characteristics in decision-making. Moreover, it enhances the understanding of SMEs on the role of cloud computing, in light of competitive business environments. Future studies have the opportunity to expand the scope to include samples from other geograpical areas and enhance data collection through case studies and interviews to understand the issue in-depth.
\end{abstract}

Keywords: management accounting information (MAI), cloud computing, decision-making, SMEs

\section{ARTICLE INFO}

\section{Article History:}

Received: 11 March 2020

Accepted: 19 March 2021

Published: 30 April 2021

* Corresponding Author: Ruhanita Maelah. E-mail: ruhanita@ukm.edu.my 


\section{INTRODUCTION}

Small and medium-sized enterprises (SMEs) are still at the early stage of development and are still evolving. Their environment can be characterised as hyper-competitive, changing, and technologically complex (Christauskas $\&$ Miseviciene, 2012). SMEs are facing challenges due to their limitations in the areas of finance and human resources as well as lack of technological adoption and information compared to large-sized companies (Ting, 2004). As such, from the resource constraint's perspective, SMEs are different from their large-sized counterparts. Despite their constraints of being small and having limited resources, management accounting information (MAI) is pertinent to the effectiveness and efficiencies of their businesses (Ahmad, 2017).

MAI is defined as an information source which contains information that is both financial and non-financial in nature. It is for the utilization of internal users for their organization's long term well-being; i.e. planning, implementation and appraisals of strategies (Hui \& Yusof, 2010). MAI provides information for various purposes spanning from decision-making to as a means of organisational learning. MAI is the basic source of information for an organization's planning, decision-making and monitoring (Ahmad, 2012; Laitinen, 2014). Abu Bakar (2001), and Hui and Yusof (2010) reported that it is helpful and vital to managers in assisting their decision-making, performance appraisal and communication. MAI can serve multiple roles simultaneously and is relevant to managers at all levels (Fitsum, 2014). In Malaysia, earlier studies focused mainly on management accounting practices (Azhar, 2005; Rahman et al., 1997; Sulaiman et al., 2004) with very little emphasis on MAI (Hui \& Yusof, 2010). Salmon and Joiner (2006) only focused on the contextual conditions for MAI. The research on SMEs in terms of management accounting is scarce (Ahmad, 2013). According to Mitchell and Reid (2000), and Nandan (2010), there is not enough interest to study the availability of MAI and the utilization of management accounting among SMEs. Very few studies have been conducted on utilization of MAI among SMEs in both developed and developing economies (Alattar et al., 2009). Increasing the trust of managers about management accounting information is needed to increase the level of management accounting applications (Nguyen \& Le, 2020). 
MAI evolves and covers information which includes internal/external, financial/nonfinancial, quantitative/qualitative and historical/future type of information (Heidmann, 2008). Financial and non-financial information helps in improve decision making (Sherine \& McLellan, 2017). Examples of the information are; expenses, revenues, sales growth, capacity utilization, wastage, customer satisfaction and loyalty, product quality, and employee motivation (Mia \& Winata, 2008). Chenhall and Morris (1986), first formalized the four main features of MAI and stated that the consideration of information for decision-making can be in terms of the features of general information. They suggested that information has four characteristics; scope, timeliness, aggregation, and integration, as displayed in Figure 1.

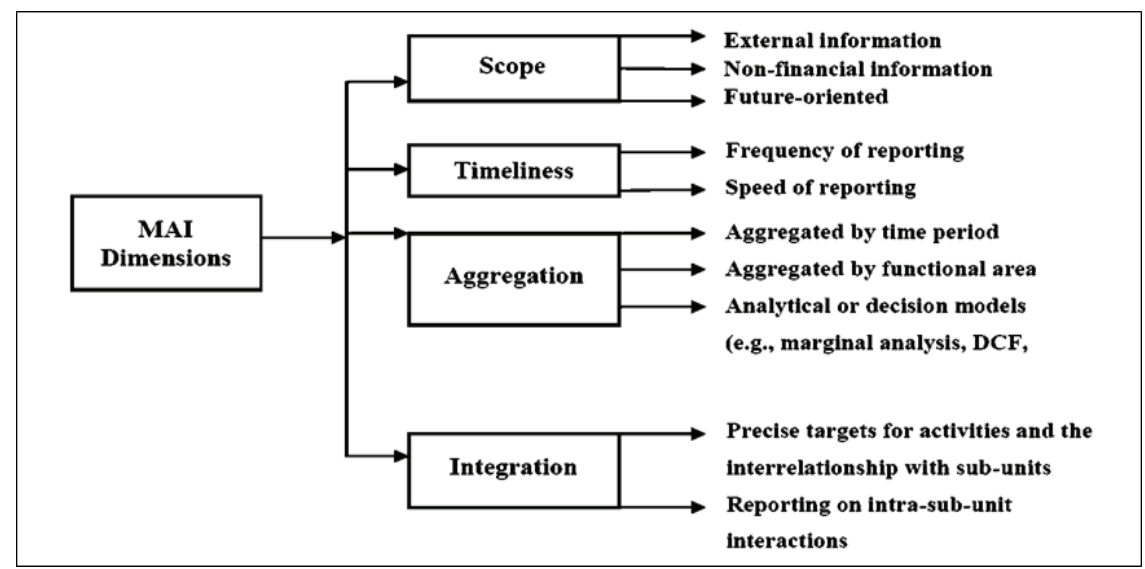

Figure 1: Information Characteristics of MAl

(Source: Chenhall and Morris, 1986)

Literature in the area of MAI indicates the importance of MAI with respect to planning, monitoring, and controlling and decision-making (Ahmad, 2012; Fitsum, 2014; Hui \& Yusof, 2010; Kaplan et al., 2011; Lim, 2011; Raman et al., 2009). Mohammed et al. (2019) indicate that SMA information (which encompasses analyses on competitors, clients and product data) has positive significant effects on firm performance.

Previous studies such as Ghasemi et al. (2016), Odar et al. (2015), and Mia and Winata (2014) adopted the instrument used by Chenhall and Morris (1986) to examine MAI. The studies addressed MAI dimensions either individually or collectively in one research setting, and only considered 
limited organisational variables in the absence of variables such as decisionmaking and technology. Most of these studies adopted the Contingency Theory to examine the relationships between the variables. This paper aimed to examine the direct influence of MAI as the independent variable with decision-making, and cloud computing. This study utilized the Resourcebased View (RBV) to determine the association between the variables.

According to Baghersefat et al. (2013), the effect of MAI on managers' decisions is an issue of certain interest among researchers. Decision-making is the backbone of managerial functions and one of the most important tasks of managers and administrators in modern organisations (Kidane, 2012). In light of the increase in competition and business uncertainty, the value of information for accurate decision making has increased (Alaarj et al., 2017). Decision making success affects firm growth (Hannimitkulchai et al., Pratoom, 2019). Researchers link the ability of making the right decision under uncertain environments to positive organizational performance (Chin et al., 2014; Jussila et al., 2016; Merigó et al., 2016). Previous studies have indicated that practices such as decision support system are used by Malaysian companies to improve the decision making process and achieve competitive advantage (Nik Abdullah, 2020; Ahmad, 2012, 2017; Nuhu et al., 2016). Findings by Mohammed et al. (2019) show that Malaysian private hospitals moderately used SMA information. To select the best choice, managers have to consider the effectiveness of the decisions. Hence, data and information may provide some guidance in achieving this (Mayr et al., 2006). A study by Hui and Yusof (2010) indicated that MAI, whether financial or non-financial, is highly useful and vital to managers in assisting them in their decision making and performance appraisal at various levels - corporate organizations, operations or functions - based on every level's requirement, resources and competence. Moreover, they also pointed out that the diagnostic and interactive functions of financial and non-financial MAI are helpful and relevant to all companies, regardless of their size.

Hui et al. (2011) reported that MAI facilitates decision-making and its well-consolidated, comprehensive and timely information may enhance the quality of managers' decisions. Another research done by Abu Bakar (2001) conducted a survey on the relationship between the availability of MAI to managers and the decision-making process, using the four dimensions of MAI adopted from Chenhall and Morris (1986). The findings suggested that 
MAI was perceived to be an essential element in assisting organisations, especially in helping managers communicate with their colleagues in the decision-making process. The findings also indicated that managers viewed all four dimensions of information to be useful to them. Whereas, a survey conducted on 449 managers from manufacturing companies in Germany by Schäffer and Steiners (2004) in the use of MAI in decision-making, monitoring and scanning found a positive association between them. Meanwhile, the research by Lim (2011) indicated that organizations utilized MAI for their various internal purposes; spanning from decision-making to as means for organizational learning. He also found that MAI facilitates organisational integration, and motivates individuals and groups by helping them in decision-makings. The use of high accounting information quality is required to improve financial reporting that will reduce the risk of making wrong decisions (Houcinel \& Kolsi, 2017).

Scholars have highlighted the role of digital technologies in enhancing productivity and performance in SMEs (Papadopoulos et al., 2020). The employment of information and communication technology (ICT) may enhance competitiveness and give real advantage to SMEs, hence allowing them to compete with large businesses (Alshamaila et al., 2013). Nugroho et al. (2017) realized that SMEs have weaknesses in the technological area. Cloud computing offers tremendous advantages to SMEs through reduced financial burden due to adoption of new technology (Carcary et al., 2014). Thus, SMEs can scale down and concentrate on their business activities as their information system and technology requirements are handled by the service providers (Tarmidi et al., 2014).

Cloud computing is a figure of speech that refers to the internet (Tarmidi et al., 2014). It is defined as “.... an information technology service model where computing services (both hardware and software) are delivered on-demand independent of device and location" (Marston et al., 2011). It is a tool that benefits its adopters significantly, such as it reduces the run and response time, minimizes the risk of physical infrastructure deployment, reduces entry cost, improves innovation speed, facilitates flexible provision of information, and uncomplicated software updates (Tsagklis, 2013). Thus, cloud computing enables organisations to extend and improve their collaboration and communication in making business decisions through access to factual and up-to-date information over the Internet regardless of their location (Dimitriu \& Matei, 2014). 
Cloud computing has been the focus of many studies (Amini, 2014). There are several previous studies which addressed cloud computing from different aspects. These studies pointed to the importance of cloud computing in information technology in contemporary organisations, and its role in flow information and access to actual and up-to-date information. Downie (1997) pointed out that the increased capacity and capability of computing technology leads to improvements of the contemporary information systems, i.e. in terms of presentation and analysis of information. Whereas, Mohammadi et al. (2015) stated that the users of cloud computing enjoy the various advantages it offers. These include acceleration of time, follow without physical presence, connect to other computer systems, availability, low-cost computers for users, increased computing power, unlimited storage, capacity building, improved matching between document formats, and access to the latest version. Abdalrahman and Mahmoud (2015) suggested that cloud computing provides the end users a service through the internet the flexibility and unlimited ability of information technology (IT) resources. Moreover, they suggested that cloud computing improves the establishment and transmission of IT solutions, particularly accounting in terms of the way financial information is exchanged and the presentation of interpreted and analysed financial data to the end user or the customer.

Furthermore, some studies have highlighted the role of cloud computing in improving access to information, and the increase in magnitude, rate, and volume of data handling that will enhance the speed and quality of decision-making throughout the organisation. Mia and Winata (2008) stated that utilization of MAI by managers in their decision-making has a positive association with ICT, which consists of a computer networks and the Internet. Moreover, they indicated that ICT utilization by managers improves the magnitude, rate and volume of data being handled and enhances the sharing of information and communication across roles, parties, places and time zones. The increased capacity of managers to immediately receive and deliver real-time information results in greater decision-making process. Similarly, the research by Quinn et al. (2014) addressed the role of cloud computing in management accounting and decision-making. They pointed out that cloud computing provides access to information for decision-making through new methods, and at various time using smart devices (tablet or smartphone). The findings showed that $93 \%$ of those interviewed agreed that the information from cloud-based systems was rated as detailed, timely 
and complete, and could promote collaboration and contribute to decisionmaking, while $90 \%$ of managers saw no disadvantages to decision-making using cloud technology.

Bachmid (2016) indicated that lack of new technology and the low level of accounting information system may cause poor performance of SMEs. In SMEs, the usage of IT is understudied and remained unique (Riemenschneider et al., 2003). The existing literatures need a comprehensive view of the IT that leads to effective utilization of accounting information systems (Klovienė \& Gimzauskiene, 2015; Bachmid, 2016). Most prior research on cloud computing concentrate on the effect of its adoption and the technical issues that arise due to its implementation (Obeidat \& Turgay, 2012). Moreover, they did not go beyond the adoption stage to examine the implementation of the system and its effectiveness in the accounting field. The advances in accounting information technology have moved towards online accounting (Christauskas \& Miseviciene, 2011). Therefore, the adoption of cloud technology by businesses is becoming important and is gaining attention (Ekufu, 2012). To date, limited studies on cloud computing in Malaysia have dealt with the factors pertaining to the adoption of cloud computing (Tarmidi et al., 2014).

Recognizing the importance of MAI and cloud computing in decision making, this study examined the influence of MAI upon SMEs in Malaysia. In particular, this study looked into the effect of MAI on organizations' decision-making process, and the moderating role of cloud computing on the association between MAI and decision-making. In the next section, the discussion on hypotheses development and research methodology are presented, followed by data analysis and discussions of findings. Finally, this paper ends with the conclusion.

\section{THEORETICAL FRAMEWORK AND HYPOTHESIS DEVELOPMENT}

This study is based on the RBV Theory which originates from the view that an organization has competitive advantage due to its internal resources. To achieve competitive advantage that is not easily imitated by competitors, resources that are valuable, scarce, not duplicable, and have no substitutes 
are needed. Resources can also be in the form of factors that can be utilized to carry-out value-creating strategies. These resources may be tangible or intangible, and encompass all assets, abilities, organizational processes, firm characteristics, information, knowledge, technology, etc. (Barney, 1991).

MAI is considered one of the valuable information resources for an organization. It is employed for many purposes such as decision-making, strategic planning and performance evaluation (Lim, 2011). Hui and Yusof (2010) suggested that the utilization of MAI helps organizations to maintain their competitive advantage and be leaders among their competitors. In addition, Gaidienë and Skyrius (2006) stressed that MAI improves decision-making, assists in strategic development, appraises current strategy, concentrates on the efforts of enhancing organizational performance and involves in the appraisals of the contributions and achievements of everyone. MAI can offer a competitive advantage to a company by providing suitable information for decision makers thereby giving it the opportunity to select the best course of action or a specific level and combination of resources to achieve its goals (Schäffer \& Steiners, 2004).

RBV emphasizes on the harmony between available opportunities and business abilities. RBV considers the utilization of available resources for creation of core competencies so that competitive advantage can be achieved and sustained (Al-Dhaafri et al., 2013). The resources can serve as the input to a process. In contrast, a capability is a resource that has the purpose of improving other resources possessed by the business (Chapman \& Wieder, 2015). Theriou et al. (2009) argued that capabilities allow the creation of relations between resources and their utilization, hence encouraging the business to create value by influencing the conversion of input into output.

Cloud computing is perceived as one of the information technology capabilities (Rockmann et al., 2014). Truong (2010) argued that cloud computing establishes and maintains competitive advantage by the association with other resources of the business. Flack and Dembla (2014) pointed out that cloud computing is an additional resource used by the firm to gain competitive advantage by propelling significant application utilization, sustaining competitiveness and reducing the cost of IT operations and maintenance. Nuseibeh (2011) stressed that cloud computing could help organisations to gain a unique competitive advantage by giving the opportunity to better interconnect and collaborate within the organisation. 
Based on the RBV perspective, the research framework is highlighted in Figure 2. MAI, as one of the organisation's resources, is expected to influence decision-making. The model illustrates the role of cloud computing as a technological capability to promote the relationship between MAI and decision-making.

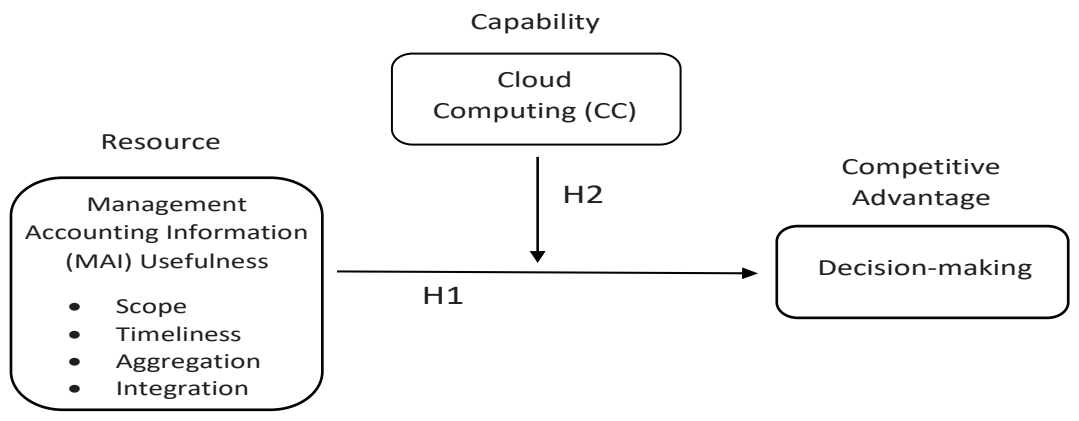

Figure 2: Research Framework

Lim (2011) indicated that MAI is capable of facilitating the integration to inspire everyone and helps in decision-making. The findings of his study documented a positive relationship between the usage of MAI in planning, for decision support, and performance evaluation. Meanwhile, Abu Bakar (2001) pointed out that MAI is perceived to be an important element in helping organisations, particularly managers, to communicate with their colleagues in the decision-making process. Hui et al. (2011) suggested MAI has an important role in the facilitation of decision-making by its supply of information. Similarly, Ahmad (2012) claimed that MAI is the main source of information for decision-making and monitoring. Therefore, the following hypothesis is proposed:

H1: There is a positive relationship between the usefulness of MAI and decision-making.

Pierce and O'Dea (2003) indicated that the wide scope of information is valuable to managers for their decision-making. Mia and Chenhall (1994) indicated that researchers agreed that the wide coverage of MAI system significantly helps managers in their decision-making. Chong (1996) discovered that for a highly uncertain situation, the extensive utilization of management accounting system results in great managerial decisions; 
thus, improving the performance of managers. Moreover, Soobaroyen and Poorundersing (2008) pointed out that the coverage and timeliness of information are vital for managers and decentralised managers in their decision-making. Therefore, the following is the hypothesis:

H1a: There is a positive relationship between the usefulness of the MAI characteristic of a broad scope and decision-making.

Hui and Yusof (2010) suggested that to make the correct decisions, information that is timely and relevant is needed. Similarly, Rahman et al. (1997) found that to decide on various problems and issues, managers require timely and accurate information. Furthermore, Ramli and Iskandar (2014) stated that timely information is valuable to decision makers as outdated information may no longer be useful in assisting the decision-making. Also, timely information assists the managers in making right decisions as it provides fast and up-to-date information. Therefore, the following is the hypothesis:

H1b:There is a positive relationship between the usefulness of the MAI characteristic of timeliness and decision-making.

Gaidienë and Skyrius (2006) stated that aggregated MAI is useful for those who make decisions and have financial responsibilities. Similarly, Choe (1998) stated that in monitoring and coordinating interdependent sub-unit's activities, managers found aggregated information to be useful to them. In addition, Ramli and Iskandar (2014) pointed out that the correct aggregated information helps in the prevention of information overload. The appraisal of relevant aggregated information is better and faster than individual information. Hui et al. (2011) found the MAI's aggregatedinformation to be useful to managers as it enhances the quality of decisions. Therefore, the following is the hypothesis:

H1c: There is a positive relationship between the usefulness of the MAI characteristic aggregation and decision-making.

Salmon and Joiner (2006) stated that MAI harmonizes the sections in a sub-unit, as well as among sub-units, where the manager is responsible for the information concerning the impact that their decision will have on 
the organisational sub-unit. Mayr et al. (2006) found that the integration of MAI has the ability to influence the decision process at almost every stage. Furthermore, Abu Bakar (2001) pointed out that the integration of information within sub-units will help managers of different departments to easily obtain useful information from other departments. Therefore, the following is the hypothesis:

H1d:There is a positive relationship between the usefulness of the MAI characteristic integration and decision-making.

Chang et al. (2003) suggested that information processing that is effective assists the smooth delivery of information to managers. Business can gain significant competitive advantage through better and faster decisions. Ekufu (2012) stated that cloud computing improves information access, assists managers by presenting methods, improves communication in the organization, and increases productivity. Additionally, it assists in critical decision-making by providing real-time information. Kinkela (2013) found that the use of cloud computing leads to efficiencies through the utilization of an outside expert who is capable to immediately modify the software instead of sending patches to meet users' needs. Furthermore, in view that users can log-in safely and remotely, cloud facilitates the transmission of data and software. With cloud computing, the organisation can make decisions faster; by communicating better through sharing and receiving information on the cloud with only a network connection, the access of files and software can be done from any device at various times (Quinn et al., 2014). Therefore, the following is the hypothesis:

H2: Cloud computing moderates the relationship between MAI and decision-making.

\section{RESEARCH METHODOLOGY}

\section{Data Collection}

The large number of SMEs in Malaysia made it impractical to include all SMEs in this study. The questionnaires were distributed to SMEs located in certain geographical areas, Selangor, Kuala Lumpur, and Johor. These 
areas have an estimated total of 279,457 SMEs, which represented 43.3\% of SMEs in Malaysia (Malaysian SME statistics 2016). SMEs can be defined by sales turnover or number of full-time staff. Medium sized firm has sales turnover of less than RM50 million or full-time staff is less than 200. Small-sized firm has sales turnover of less than RM20 million or its full-time staff is less than 75 (SME Corp. Malaysia, 2013).

This unit of analysis was small and medium-sized companies from various industries, and the participants for this study were owner/manager of SMEs, which is similar to the approach taken by prior studies (Ahmad, 2012, Ahmad et al., 2015; Koe et al., 2015; Lybaert, 1998). A stratified random sampling was adopted because there are several different industries in the SME sector. A stratified random sample provides the same chance for all population units to be included in the selected sample, which provides a high level of generalizability (Bryman, 2007).

The questionnaire method was utilized to collect the data. Keillor et al. (2001) stated that the questionnaire technique is considered to be the most commonly used survey method. Whereas, Moilanen (2001) argued that the questionnaire technique is appropriate for different levels including the organisational level. To improve the questionnaire's reliability, a pre-test was conducted prior to the actual gathering of data. A total of 384 printed questionnaires were distributed for this study. For each company selected, a questionnaire and a letter specifying the goal of the current study were distributed to the owner/manager of the SMEs. A total of 105 responses were obtained. Kent (2001) suggested that for quantitative analysis to have sensible statistical analysis and meaningful results, a study needs to have at least 100 responses. The response rate of $27 \%$ is considered reasonable in the case of the Malaysian environment. Based on past studies, the response rate in Malaysia was between 15\% and 30\% (Omar \& Ali, 2010).

\section{Variable Measurements}

The questionnaire items were adopted from previous literature. A total of 19 questions were used from (Haedr, 2012) with regard to the four dimensions of MAI, namely scope, timeliness, aggregation and integration. For this section, questions with two-sided 5-point scales were used. The scales with regard to importance of MAI were positioned at the left side, 
ranging from 1 (not important) to 5 (very important). Meanwhile, for MAI availability, the scales were on the right-side, ranging from 1 (not available) to 5 (always available). The usefulness of MAI characteristics is perceived through its importance and availability. Therefore, the scores for each item obtained from both scales (importance and availability) were used to determine the usefulness of MAI (Maelah et al., 2019).

To capture cloud computing service, this study used seven items adopted from Monteiro and Vasconcelos (2013). The respondents were required to rate the quality of cloud computing service provided to the organization based on a 5-point Likert scale ranging from 1(not important) to 5(very important). A similar scale has been used by previous studies (Garg et al., 2011, 2013; Siegal \& Purdue, 2012) to measure the service quality of cloud computing. With regard to decision-making, this study utilized six items developed by Awasthi and Varman (2003). The respondents were asked to evaluate the quality of decision-making in their organisations based on 5-point scale from 1 (strongly disagree) to 5 (strongly agree). The measurements of the variables are summarized in Table 1.

Table 1: Variable Measurements

\begin{tabular}{|c|c|c|c|c|}
\hline Variable & Dimension & Source & Item & Scale \\
\hline $\mathrm{MAI}$ & $\begin{array}{l}\text { Scope } \\
\text { Timeliness } \\
\text { Aggregation } \\
\text { Integration }\end{array}$ & $\begin{array}{l}\text { (Chenhall \& } \\
\text { Morris, 1986) } \\
\text { and (Gordon } \\
\& \text { Narayanan, } \\
\text { 1984), which } \\
\text { has been further } \\
\text { modified by } \\
\text { (Haedr, 2012). }\end{array}$ & $\begin{array}{l}6 \\
4 \\
5\end{array}$ & $\begin{array}{l}5 \text {-point scale; the scales } \\
\text { related to the MAI importance } \\
\text { from ( } 1=\text { not important, } 5= \\
\text { very important). Meanwhile, } \\
\text { the scales related to the } \\
\text { MAl availability are from } \\
\text { ( } 1=\text { not available, } 5=\text { always } \\
\text { available). MAI Usefulness } \\
\text { (Importance*Availability) }\end{array}$ \\
\hline $\begin{array}{l}\text { Cloud } \\
\text { Computing }\end{array}$ & & $\begin{array}{l}\text { (Monteiro \& } \\
\text { Vasconcelos, } \\
\text { 2013) }\end{array}$ & 7 & $\begin{array}{l}\text { 5-point Likert scale }(1=\text { not } \\
\text { Important, } 5=\text { Very Important). }\end{array}$ \\
\hline $\begin{array}{l}\text { Decision } \\
\text { Making }\end{array}$ & & $\begin{array}{l}\text { (Awasthi \& } \\
\text { Varman, 2003) }\end{array}$ & 6 & $\begin{array}{l}5 \text {-point Likert scale }(1= \\
\text { strongly disagree, } 5=\text { strongly } \\
\text { agree). }\end{array}$ \\
\hline
\end{tabular}

Data was analysed using the Smart Partial Least Squares (PLS) to assess the validity and reliability, and test the research hypotheses. The first hypothesis was the direct relationship between MAI and decision making. Four sub-hypothesis encompassing the relationship between 
scope, timeliness, aggregation and integration of MAI and decision making were also tested. The second hypothesis was the moderating role of cloud computing on the relationship between MAI and decision making. Smart PLS provides latent variable scores; avoids small sample size problems; estimates complex models with many latent and manifest variables, and error terms; it does not impose any normality requirements on the data; examines the theory and measures simultaneously; and handles both reflective and formative measurement models (Henseler \& Chin 2010). The PLS model is analysed and interpreted in two stages: (1) The measurement model that displays the relationships between the constructs and the indicator, and assesses the reliability and validity of the measurement model; and (2) The structural model, which represents the constructs and displays the relationships (paths) between the constructs (Hair et al., 2017).

\section{DATA ANALYSIS AND RESULTS}

\section{Demographic Statistics}

Frequency and percentage were used to develop the profile of the respondents for this study. As shown in Table 2, the vast majority, of the respondents were under 30 years old (41\%), had bachelor's degree (61\%), specialized in accounting/finance (35.2\%) and have less than 5-year experience $(36.2 \%)$. By looking at the job title and position, $29.5 \%$ of the respondents were managerial accountants, $14.3 \%$ finance managers, $8.6 \%$ general managers, followed by $4.8 \%$ marketing managers, $1.9 \%$ production managers and $41 \%$ others. Although 'others' represented $41 \%$ of the respondents, the data showed that $60 \%$ of 'others' were directors, administration managers, HR managers, CEOs, and executive managers. The demographic analysis of the respondents indicated that the sample was well represented by various age groups, qualifications, and experience. 
Table 2: Demographic Profiles of Respondents ( $N=105)$

\begin{tabular}{|c|c|c|c|c|c|c|c|}
\hline No. & Demographic Variable & Frequency & $\%$ & No. & $\begin{array}{l}\text { Demographic } \\
\text { Variable }\end{array}$ & Frequency & $\%$ \\
\hline \multirow[t]{5}{*}{1} & Age group & & & 4 & Job title and position & & \\
\hline & Under 30 & 43 & 41.0 & & General Manager & 9 & 8.6 \\
\hline & 30 to 40 & 36 & 34.3 & & Marketing manager & 5 & 4.8 \\
\hline & $41-50$ & 13 & 12.4 & & $\begin{array}{l}\text { Managerial } \\
\text { accountant }\end{array}$ & 31 & 29.5 \\
\hline & Over 50 & 13 & 12.4 & & Production manager & 2 & 1.9 \\
\hline \multirow[t]{6}{*}{2} & Qualification/Education & & & & Finance manager & 15 & 14.3 \\
\hline & High School & 6 & 5.7 & & Other* & 43 & 41 \\
\hline & College diploma & 12 & 11.4 & 5 & Experiences & & \\
\hline & Professional Qualification & 9 & 8.6 & & Less than 5 years & 38 & 36.2 \\
\hline & Bachelor degree & 64 & 61 & & 5 to 10 years & 28 & 26.7 \\
\hline & Post-graduate degree & 14 & 13.3 & & 11 to 15 years & 18 & 17.1 \\
\hline \multirow[t]{6}{*}{3} & Area of specialization & & & & 16 to 20 years & 9 & 8.6 \\
\hline & Accounting/Finance & 37 & 35.2 & & Over 20 years & 11 & 10.5 \\
\hline & Business Administration & 33 & 31.4 & & & & \\
\hline & Economic & 2 & 1.9 & & & & \\
\hline & Computer Science & 8 & 7.6 & & & & \\
\hline & Others & 25 & 23.8 & & & & \\
\hline
\end{tabular}

*Other (Directors, Administration Managers, HR Managers, CEO, and Exec Managers)

As shown in Table 3, 66.7\% of the companies were service companies, followed by $25.7 \%$ manufacturing, $5.7 \%$ construction, and $1.9 \%$ agriculture. In terms of size $56.2 \%$ had between 5-29 full-time employees, and 39\% recorded between RM3 to RM21 million annual sales turnover. The results of the study revealed that $41.9 \%$ of organizations had been in operation for 10 to 20 years, followed by $37.1 \%$ for more than 20 years, $11.4 \%$ less than 5 years, and $9.5 \%$ for 5 years to less than 10 years. 
Table 3: Demographic Profiles of Companies $(\mathrm{N}=105)$

\begin{tabular}{|c|c|c|c|c|c|c|c|}
\hline No. & $\begin{array}{c}\text { Demographic } \\
\text { Variable }\end{array}$ & Frequency & $\%$ & No. & $\begin{array}{l}\text { Demographic } \\
\text { Variable }\end{array}$ & Frequency & $\%$ \\
\hline \multirow[t]{6}{*}{1} & Main industrial sector & & & 3 & Annual sales turnover & & \\
\hline & Services & 70 & 66.7 & & Less than RM3 million & 38 & 36.2 \\
\hline & Agriculture & 2 & 1.9 & & $\begin{array}{l}\text { RM3 to less than RM21 } \\
\text { million }\end{array}$ & 41 & 39.0 \\
\hline & Mining \& Quarrying & 0 & 0.0 & & RM21 to RM50 million & 26 & 24.8 \\
\hline & Manufacturing & 27 & 25.7 & & & & \\
\hline & Construction & 6 & 5.7 & 4 & Company age & & \\
\hline \multirow[t]{4}{*}{2} & Full-time employees & & & & Less than 5 years & 12 & 11.4 \\
\hline & $5-29$ & 59 & 56.2 & & $\begin{array}{l}5 \text { years to less than } 10 \\
\text { years }\end{array}$ & 10 & 9.5 \\
\hline & $30-74$ & 23 & 21.9 & & $\begin{array}{l}10 \text { years to less than } \\
20 \text { years }\end{array}$ & 44 & 41.9 \\
\hline & $75-200$ & 23 & 21.9 & & More than 20 years & 39 & 37.1 \\
\hline
\end{tabular}

\section{Hypothesis Testing}

\section{(1) Evaluation of the measurement model:}

There are two vital aspects that need consideration when utilising a survey instrument, and those are construct reliability and validity scales. Chin (1998) proposed that the Cronbach's alpha $(\alpha)$, composite reliability (CR), and average variance extracted (AVE) be used to evaluate the reflective construct properties. If the reliability exceeds 0.70 , then the construct is acceptable (Clum et al., 1990). Based on the data, the scores of both Cronbach's alpha $(\alpha)$ and (CR) exceeded 0.70, which indicated that the item construct scale for each variable has consistency reliability. Convergent validity of the measurement model can be assessed by checking whether AVE of the construct is greater than 0.50 (at the construct level), and the item loadings are greater than 0.50 and statistically significant at the item level (Hair et al., 2011). Consistent with Hair et al. (2011, 2017), the constructs and variables were satisfactory as AVE and factor loadings for each measure exceeded 0.50, as shown in Table 4 . 
Table 4: Evaluation of the Measurement Model

\begin{tabular}{|c|c|c|c|c|c|c|c|c|c|}
\hline & Loading & AVE & CR & $\begin{array}{c}\text { Cronbach } \\
\text { alpha }\end{array}$ & & Loading & AVE & CR & $\begin{array}{c}\text { Cronbach } \\
\text { alpha }\end{array}$ \\
\hline Scope & & & & & Integration & & & & \\
\hline S1 & 0.818 & 0.746 & 0.946 & 0.932 & 11 & 0.875 & 0.799 & 0.941 & 0.916 \\
\hline $\mathrm{S} 2$ & 0.890 & & & & 12 & 0.909 & & & \\
\hline S3 & 0.888 & & & & 13 & 0.909 & & & \\
\hline S4 & 0.836 & & & & 14 & 0.883 & & & \\
\hline S5 & 0.855 & & & & $\begin{array}{l}\text { Cloud } \\
\text { Computing }\end{array}$ & & & & \\
\hline S6 & 0.893 & & & & CC1 & 0.698 & 0.562 & 0.9 & 0.871 \\
\hline Timeliness & & & & & $\mathrm{CC} 2$ & 0.696 & & & \\
\hline $\mathrm{T} 1$ & 0.944 & 0.882 & 0.968 & 0.955 & CC3 & 0.785 & & & \\
\hline T2 & 0.942 & & & & CC4 & 0.779 & & & \\
\hline T3 & 0.937 & & & & CC5 & 0.773 & & & \\
\hline $\mathrm{T} 4$ & 0.933 & & & & CC6 & 0.769 & & & \\
\hline Aggregation & & & & & CC7 & 0.744 & & & \\
\hline $\mathrm{A} 1$ & 0.894 & 0.788 & 0.949 & 0.933 & $\begin{array}{l}\text { Decision } \\
\text { Making } \\
\end{array}$ & & & & \\
\hline $\mathrm{A} 2$ & 0.879 & & & & DM1 & 0.857 & 0.751 & 0.948 & 0.934 \\
\hline A3 & 0.905 & & & & DM2 & 0.841 & & & \\
\hline A4 & 0.891 & & & & DM3 & 0.872 & & & \\
\hline A5 & 0.869 & & & & DM4 & 0.844 & & & \\
\hline & & & & & DM5 & 0.876 & & & \\
\hline
\end{tabular}

The issues of discriminant validity appear when constructs are similar to each other (Straub et al., 2004). In PLS, AVE analysis is done to examine the measurement model's discriminant validity. Consistent with the guidelines of Fornell and Larcker (1981), should the AVE is more than the squared correlation, then there is sufficient discriminant validity. Based on Table 5, each construct's AVE exceeded the squared correlation. Thus, all constructs had sufficient discriminant validity. 
Table 5: The Result of Discriminant Validity

\begin{tabular}{|c|c|c|c|c|c|c|c|}
\hline & AVE & Aggregation & $\begin{array}{l}\text { Cloud } \\
\text { computing }\end{array}$ & $\begin{array}{l}\text { Decision- } \\
\text { making }\end{array}$ & Integration & Scope & Timeliness \\
\hline Aggregation & 0.788 & 0.888 & & & & & \\
\hline $\begin{array}{l}\text { Cloud } \\
\text { computing }\end{array}$ & 0.562 & 0.366 & 0.750 & & & & \\
\hline $\begin{array}{l}\text { Decision } \\
\text { making }\end{array}$ & 0.751 & 0.597 & 0.465 & 0.867 & & & \\
\hline Integration & 0.799 & 0.629 & 0.498 & 0.613 & 0.894 & & \\
\hline Scope & 0.746 & 0.558 & 0.177 & 0.497 & 0.417 & 0.864 & \\
\hline Timeliness & 0.882 & 0.354 & 0.293 & 0.472 & 0.452 & 0.304 & 0.939 \\
\hline
\end{tabular}

\section{(2) Evaluation of the structural model:}

To verify the hypotheses in this study, the t-value and P-value were derived using the bootstrapping procedure to consider path significance. The strength and significance of the associations between the dependent and independent variables are shown by path coefficients. Generally, a t-value larger than 1.96 (t-value >1.96) is significant (Hair et al., 2011). According to Ifinedo (2011), a P-value $<0.05$ indicates a relationship's significance between variables. The R-square of decision making was 0.566 indicating that $56.6 \%$ of the variation in decision making of Malaysian SMEs can be explained by MAI and cloud computing. R-squared value $0.5<\mathrm{r}<0.7$ is generally considered a moderate effect size (Moore et al., 2013). Table 6 shows the summaries of the results of the t-value and P-value and the final results for each hypothesis. Based on this results, we conclude that all the hypotheses are accepted.

Table 6: Summaries of the Results

\begin{tabular}{|c|c|c|c|}
\hline Hypothesis & T-Value* & P-Value ** & Results \\
\hline H1: The usefulness of the MAI -> Decision-making & 9.897 & 0.001 & Accepted \\
\hline $\begin{array}{l}\text { H1a: The usefulness of the MAI characteristic of broad } \\
\text { scope -> Decision-making }\end{array}$ & 2.005 & 0.045 & Accepted \\
\hline $\begin{array}{l}\text { H1b: The usefulness of the MAI characteristic of } \\
\text { timeliness }->\text { Decision-making }\end{array}$ & 2.12 & 0.034 & Accepted \\
\hline $\begin{array}{l}\text { H1c: The usefulness of the MAI characteristic of } \\
\text { aggregation } \rightarrow \text { Decision-making }\end{array}$ & 2.454 & 0.014 & Accepted \\
\hline $\begin{array}{l}\text { H1d: The usefulness of the MAI characteristic of } \\
\text { integration } \rightarrow>\text { Decision-making }\end{array}$ & 2.878 & 0.004 & Accepted \\
\hline $\begin{array}{l}\text { H2: Moderating effect cloud computing }->\mathrm{MAI} \text { and } \\
\text { Decision-making }\end{array}$ & 2.674 & 0.008 & Accepted \\
\hline
\end{tabular}




\section{Results and Discussion}

The first objective of this study was to examine the effect of MAI on decision-making. The discussion below focuses on the results of hypothesis testing.

H1: There is a positive relationship between the usefulness of MAI and decision-making.

The findings of the study revealed a significant relationship between the usefulness of MAI and decision-making $(b=0.626, t=9.897, p<0.05)$. Therefore, this finding is similar to the findings of past studies (Akbar, 2010; Abu Bakar, 2001; Fitsum, 2014; Lim, 2011; Mia \& Patiar, 2001). Houcinel and Kolsi (2017) and Lim (2011) suggested quality information improved decision making. MAI is perceived to be an important element in helping modern organisations, particularly managers in decision-making in SMEs in Malaysia. SME companies perceive that MAI is useful in improving the decision-making processes in a competitive condition by helping them to make sound decisions based on the information provided. Nevertheless, these companies perceived that for them to maintain their effectiveness and competitiveness, more information is needed.

H1a: There is a positive relationship between the usefulness of the MAI characteristic of broad scope and decision-making.

The results of the study indicated a significant relationship between the MAI characteristic of usefulness in broad scope and decision-making $(b=0.179, t=2.005, p<0.05)$, which supports the previous studies that reported the influence of broad scope MAI on decision-making (Chenhall \& Morris, 1986; Chong, 1996; Mia \& Chenhall, 1994). Soobaroyen and Poorundersing (2008) addressed the importance of information coverage in decision making. That MAI characteristic of broad scope is perceived as being one of the useful MAI characteristics in organisations, which provides financial and non-financial information of the internal and external environments of an organisation. The surveyed SMEs perceived that the MAI characteristic of broad scope helps managers to obtain greater information about their competitors and future events. Also, they confirmed the desire of decision-makers in their organisations for wide information that provides them with useful information related to their decisions area. 
H1b: There is a positive relationship between the usefulness of the MAI characteristic of timeliness and decision-making.

The results showed that relationship between the usefulness of the MAI characteristic of timeliness and decision-making $(b=0.198, t=2.12, p<0.05)$ is significant. This finding is consistent with the findings of earlier studies (Abu Bakar, 2001; Chenhall \& Morris, 1986; Fitsum, 2014; Haedr, 2012). Ramli and Iskandar (2014) and Hui and Yusof (2014) emphasized that timely information is necessary for decision making. The MAI characteristic of timeliness is about how fast and often the reporting is, and the information is furnished when asked. Hence, allowing the SMEs to respond expeditiously and make effective decisions soonest possible. From the findings, we conclude that SME companies perceive more frequent or timely information as important to organizational success. Specifically, SMEs' managers prefer up-to-date information. It is seen as information that is presented upon request, more frequent, shows current scenario and responds fast to their decisions. In short, the usefulness of the MAI characteristic of timeliness is perceived by SMEs to be valuable to support their decisions.

H1c: There is a positive relationship between the usefulness of the MAI characteristic of aggregation and decision-making.

The results of the study showed a significant relationship between the usefulness of the MAI characteristic of aggregation and decision-making $(b=0.244, t=2.454, p<0.05)$, similar to studies reported in the literature (Abu Bakar, 2001; Fitsum, 2014; Lederer \& Smith Jr, 1988; Odar et al., 2015). Ramli and Iskandar (2014) pointed out the importance of aggregated information to avoid information overload. The MAI characteristic of aggregation involves summarising information across different periods and departments, which allows decision makers to consider more alternatives in making optimal decisions for SMEs in Malaysia. SMEs depend on the aggregated MAI to obtain information related to functional activities from other departments within the organisation. Furthermore, the aggregated MAI is seen to be more useful by SMEs' managers from different functional levels to assist them in their daily operations as well as in making decisions for the benefit of their organizations.

H1d:There is a positive relationship between the usefulness of the MAI characteristic of integration and decision-making. 
There is significant relationship between the usefulness of the MAI characteristic of integration and decision-making $(b=0.296, t=2.878$, $\mathrm{p}<0.05$ ). This finding is similar to previous studies (Abu Bakar, 2001; Chenhall \& Morris, 1986; Fitsum, 2014; Ghasemi et al., 2016; Odar et al., 2015), in that the MAI characteristic of integration is perceived as being the most important dimension among all four MAI dimensions in SMEs in Malaysia. Integration refers to the various departments' interdependence and coordination in the sharing of information throughout the organization. SMEs perceived integrated MAI to be useful by allowing information sharing between each department and sub-units. SMEs' managers see integrated MAI as important in the coordination between departments or sub-units to obtain beneficial information related to their decisions.

The second objective of this study was to examine the moderating effect of cloud computing in the association between management accounting information and decision-making.

H2: Cloud computing moderates the relationship between MAI and decision-making.

Cloud computing moderates the relationship between MAI and decision-making $(b=-0.111, t=2.674, p<0.05)$. The results of the analysis revealed that cloud computing strengthens the relationship between MAI and decision-making in SMEs in Malaysia. The result is similar to the studies examining the role of cloud computing in improving the access and share of information in real-time, and increasing the volume, speed, and capacity of data handling that will enhance the timeliness and quality of decision-making in the organisation, particularly in SMEs. Quinn et al. (2014) pointed out that cloud computing allows new methods for SME managers to obtain decision-making information, in that cloud computing allows managers to access information whenever they require it through smart devices (tablet or smartphone) at a relatively low cost. Marand et al. (2013) stated that cloud computing plays a vital role in the delivering of decision-making information by enhancing information accessibility; data analysis; providing continuous auditing; and information storage. Mia and Winata (2008) argued that the utilization of MAI by managers for decision-making has a positive relationship with cloud computing through the increase in the capacity of managers to immediately access real-time information, hence facilitating faster and effective decision-making. 
From the findings, we conclude that cloud computing plays a vital role in SMEs in Malaysia through its role in the flow of information and access to actual and up-to-date information that enhances the speed and quality of decision-making. In addition, it improves business competitiveness for SMEs by reducing the cost load associated with the adoption of modern information technology and by being able to focus more on the business. Based on the findings, SMEs in Malaysia should concentrate on cloud computing to improve the access and share of the information used for decision-making in their organisations. Findings of this study provide signals on the extent of technology utilisation among SMEs in Malaysia. The findings indicate the awareness and utilization of cloud computing among SMEs should be further improved.

\section{CONCLUSION}

SMEs are important contributors to the growth of Malaysia. In today's business environment, information and technology plays a vital role in SMEs operations. This study examined the relationships between MAI, cloud computing and decision making in SMEs. The main contribution of this study is to provide empirical evidence concerning the influence of MAI on decision-making and the moderating role of cloud computing in the relationship. The findings contribute to the body of knowledge in the area of management accounting through usage of the RBV Theory to explain MAI as a resource, and cloud computing as a capability to gain competitive advantage in decision making. Moreover, the findings of this study contribute by helping organizations to realize the importance of MAI in managerial tasks, and how they could rely on a selection of information characteristics in the context of their business environment to ensure competitiveness of the company in the marketplace. The findings may also enhance the understanding of SMEs' managers on the importance of cloud computing to improve decision-making in the light of competition. Thus, the findings of this study can be used to determine the effectiveness of existing policies and initiatives as well as the direction sets for the SMEs, with regard to information quality, IT and competitiveness.

This study has several constraints. First, this study took only SMEs in Malaysia as its sample. Thus, the findings could not be generalized to 
large businesses or SMEs in other countries. Consequently, future studies may replicate this study on large businesses in Malaysia or other economies (developed or developing economy). Second, this study was confined to certain geographical areas of Malaysia, providing opportunities for future studies to expand the scope to other locations in Malaysia. Third, this study suffered from a comparatively low response rate for its questionnaire survey as a result of the sensitivity and confidentiality of the data required, and cloud computing is a new technology among SMEs in Malaysia. For future research a combination of online survey questionnaires may be used to reach more respondents, while interviews and case studies may be utilized to understand the issue in-depth.

\section{ACKNOWLEDGEMENT}

We would like to extend our appreciation to Universiti Kebangsaaan Malaysia for funding part of this research project (EP-2018-001).

\section{REFERENCES}

Abdalrahman, A. E. M., \& Mahmoud, A. M. M. (2015). Electronic accounting applications using cloud computing technology. Journal of Information Sciences and Computing Technologies, 4(2), 297-302.

Ahmad, K. (2012). The use of management accounting practices in Malaysian SMEs (Doctoral dissertation, University of Exeter, United Kingdom).

Ahmad, K. (2013). The adoption of management accounting practices in Malaysian small and medium-sized enterprises. Asian Social Science, 10(2), 236-249.

Ahmad, K. (2017). The implementation of management accounting practices and its relationship with performance in small and medium enterprises. International Review of Management and Marketing, 7(1), 342-353.

Ahmad, S. Z., Abu Bakar, A. R., Faziharudean, T. M., \& Mohamad Zaki, K. A. (2015). An empirical study of factors affecting e-commerce adoption 
among small-and medium-sized enterprises in a developing country: Evidence from Malaysia. Information Technology for Development, 21(4), 555-572.

Akbar, S. (2010). Management accounting change: A comparative study of Indian and UK organisations. Journal for Global Business Advancement, 3(1), 1-27.

Alaarj, S., Mohamed, Z. A., \& Bustamam, U. S. A. (2017). Do knowledge management capabilities reduce the negative effect of environment uncertainties on organizational performance? A study of public listed companies in Malaysia. International Journal of Economic Research, 14(15), 443-456.

Abu Bakar, N. (2001). The availability of management accounting information and its usefulness to managers in the manufacturing sector (Doctoral dissertation, Universiti Teknologi MARA, Malaysia).

Alattar, J. M., Kouhy, R., \& Innes, J. (2009). Management accounting information in micro enterprises in Gaza. Journal of Accounting \& Organizational Change, 5(1), 81-107.

Al-Dhaafri, H. S., Yusoff, R. Z. B., \& Al-Swidi, A. K. (2013). The effect of total quality management, enterprise resource planning and the entrepreneurial orientation on the organizational performance: The mediating role of the organizational excellence - A proposed research framework. International Journal of Business Administration, 4(1), 66-85.

Alshamaila, Y., Papagiannidis, S., \& Li, F. (2013). Cloud computing adoption by SMEs in the north east of England: A multi-perspective framework. Journal of Enterprise Information Management, 26(3), 250-275.

Amini, M. (2014). The factors that influence on adoption of cloud computing for small and medium enterprises (Master's thesis, Universiti Teknologi Malaysia, Malaysia). 
Awasthi, A., \& Varman, R. (2003). Investigating the influence of information technology on decision making. Journal of Advances in Management Research, 1(1), 74-87.

Azhar, Z. (2005). Application of management accounting techniques in Malaysian higher learning institutions: A survey of practices (Doctoral dissertation, Universiti Teknologi Mara, Malaysia).

Bachmid, F. S. (2016). The effect of accounting information system quality on accounting information quality. Research Journal of Finance and Accounting, 7(20), 26-31.

Baghersefat, M. J., Zareei, M. H., Bazkiai, M. J., \& Siavorodi, R. I. (2013). Estimate role of accounting information systems in presentation managers required information. Interdisciplinary Journal of Contemporary Research in Business, 4(12), 511-518.

Barney, J. (1991). Firm resources and sustained competitive advantage. Journal of Management, 17(1), 99-120.

Bryman, A. (2007). Barriers to integrating quantitative and qualitative research. Journal of Mixed Methods Research, 1(1), 8-22.

Carcary, M., Doherty, E., \& Conway, G. (2014). The adoption of cloud computing by Irish SMEs - An exploratory study. Electronic Journal Information Systems Evaluation Volume, 17(1), 3-14.

Chang, R.-D., Chang, Y.-W., \& Paper, D. (2003). The effect of task uncertainty, decentralization and AIS characteristics on the performance of AIS: An empirical case in Taiwan. Information \& Management, 40(7), 691-703.

Chapman, P., \& Wieder, B. (2015). IT governance as a higher order capability. Pacific Asia Conference on Information Systems, PACIS 2015-Proceedings. Retrieved from https://aisel.aisnet.org/ pacis2015/150/ 
Chenhall, R. H., \& Morris, D. (1986). The impact of structure, environment, and interdependence on the perceived usefulness of management accounting systems. Accounting Review, 61(1), 16-35.

Chin, T. A., Hamid, A. B. A., Rasli, A., \& Tat, H. H. (2014). A literature analysis on the relationship between external integration, environmental uncertainty and firm performance in Malaysian SMEs. Procedia-Social and Behavioral Sciences, 130, 75-84.

Chin, W. W. (1998). The partial least squares approach to structural equation modeling. Modern Methods for Business Research, 295(2), 295-336.

Choe, J.-M. (1998). The effects of user participation on the design of accounting information systems. Information \& Management, 34(3), 185-198.

Chong, V. K. (1996). Management accounting systems, task uncertainty and managerial performance: A research note. Accounting, organizations and Society, 21(5), 415-421.

Christauskas, C., \& Miseviciene, R. (2011). Online accounting software for the business.

Christauskas, C., \& Miseviciene, R. (2012). Cloud-computing based accounting for small to medium sized business. Engineering Economics, 23(1), 14-21.

Clum, G. A., Broyles, S., Borden, J., \& Watkins, P. L. (1990). Validity and reliability of the panic attack symptoms and cognitions questionnaires. Journal of Psychopathology and Behavioral Assessment, 12(3), 233245.

Department of Statistics, Malaysia and SME Corp. Malaysia. (2011). SME Statistics. Available at: http://www.smecorp.gov.my/index.php/en/pol icies/2015-12-21-09-09-49/sme-statistics (accessed March 28, 2017).

Dimitriu, O., \& Matei, M. (2014). The expansion of accounting to the cloud. SEA-Practical Application of Science, 2(4), 237-240. 
Downie, N. (1997). The use of accounting information in hotel marketing decisions. International Journal of Hospitality Management, 16(3), 305-312.

Ekufu, T. K. (2012). Predicting cloud computing technology adoption by organizations: An empirical integration of technology acceptance model and theory of planned behavior (Doctoral dissertation, Capella University).

Fitsum, K. W. (2014). The role of management accounting information systems on managerial decisions in printing industry in Ethiopia: The case of medium and large scale printing companies (Doctoral dissertation, Andhra University).

Flack, C. K., \& Dembla, P. (2014, March). Influence of cloud-based computing on user productivity. Paper presented at the Southern Association for Information Systems Conference, Macon, GA, USA.

Fornell, C., \& Larcker, D. F. (1981). Evaluating structural equation models with unobservable variables and measurement error. Journal of Marketing Research, 18(1), 39-50.

Gaidienë, Z., \& Skyrius, R. (2006). The usefulness of management accounting information: Users'attitudes. Ekonomika, 74, 21-37.

Garg, S. K., Versteeg, S., \& Buyya, R. (2011). Smicloud: A framework for comparing and ranking cloud services. Paper presented at the 2011 Fourth IEEE International Conference on Utility and Cloud Computing.

Garg, S. K., Versteeg, S., \& Buyya, R. (2013). A framework for ranking of cloud computing services. Future Generation Computer Systems, 29(4), 1012-1023.

Ghasemi, R., Mohamad, N. A., Karami, M., Bajuri, N. H., Asgharizade, E., \& Liu, M. (2016). The mediating effect of management accounting system on the relationship between competition and managerial performance. International Journal of Accounting \& Information Management, 24(3), 272-295. 
Gordon, L.A., \& Narayanan, V. K. (1984). Management accounting systems, perceived environmental uncertainty and organization structure: An empirical investigation. Accounting, Organizations and Society, 9(1), $33-47$.

Haedr, A. R. (2012). A contingency theory-based investigation of the role of management accounting information in management control systems in large manufacturing companies in Libya (Doctoral dissertation, University of Huddersfield).

Hair, J. F., Hult, G. T. M., Ringle, C. M., \& Sarstedt, M. (2017). A primer on partial least squares structural equation modeling (PLS-SEM) $\left(2^{\text {nd }}\right.$ ed.). Thousand Oaks, CA: Sage.

Hair, J. F., Ringle, C. M., \& Sarstedt, M. (2011). PLS-SEM: Indeed a silver bullet. Journal of Marketing theory and Practice, 19(2), 139-152.

Hannimitkulchai, K., Phornlaphatrachakorn, K., \& Pratoom, K. (2019). Dynamic management accounting orientation and firm growth: Empirical evidence from food businesses in Thailand. Journal of Multidisciplinary in Social Sciences, 15(1), 78-89.

Heidmann, M. (2008). The role of management accounting systems in strategic sensemaking. Wiesbaden, Germany: Springer.

Houcinel, A., \& Kolsi, M. C. (2017). The effect of financial reporting quality on corporate investment efficiency: Evidence from the Tunisian Stock Market. Research in International Business and Finance, 42, 321-337.

Hui, W. S., \& Yusof, N. A. B. M. (2010, December). The use of management accounting information (MAI): Perceptions of preparers and users. Paper presented at the International Conference on Science and Social Research (CSSR) 2010.

Hui, W. S., Rahman, I. K. A., \& Juan, D. (2011, June). The importance of management accounting information in the transformation process of a government-linked company. Paper presented at the 2011 International Symposium on Humanities, Science and Engineering Research. 
Ifinedo, P. (2011). An empirical analysis of factors influencing Internet/ebusiness technologies adoption by SMEs in Canada. International Journal of Information Technology \& Decision Making, 10(04), 731766.

Jussila, A., Mainela, T., \& Nätti, S. (2016). Formation of strategic networks under high uncertainty of a megaproject. Journal of Business \& Industrial Marketing, 31(5), 575-586.

Kaplan, R., Atkinson, A., \& Young, S. (2011). Management accounting: Information for decision making and strategy execution. Upper Saddle River, New Jersey: Pearson Education.

Keillor, B., Owens, D., \& Pettijohn, C. (2001). A cross-cultural/crossnational study of influencing factors and socially desirable response biases. International Journal of Market Research, 43(1), 63-84.

Kent, R. (2001). Data construction and data analysis for survey research. Basingstoke, United Kingdom: Palgrave MacMillan.

Kidane, F. (2012). Decision making and the role of management accounting function - A review of empirical literature. Radix International Journal of Banking, Finance and Accounting, 1(4), 77-97.

Kinkela, K. (2013). Practical and ethical considerations on the use of cloud computing in accounting. Journal of Finance and Accountancy, 14, $1-10$.

Kloviene, L., \& Gimzauskiene, E. (2015). The effect of information technology on accounting system's conformity with business environment: A case study in banking sector company. Procedia Economics and Finance, 32, 1707-1712.

Koe, W.-L., Omar, R., \& Sa'ari, J. R. (2015). Factors influencing propensity to sustainable entrepreneurship of SMEs in Malaysia. Procedia-Social and Behavioral Sciences, 172, 570-577.

Laitinen, E. K. (2014). The association between CEO work, management accounting information, and financial performance: Evidence from 
Finnish top managers. Journal of Management Control, 25(3-4), 221257.

Lederer, A. L., \& Smith Jr, G. L. (1988). Individual differences and decisionmaking using various levels of aggregation of information. Journal of Management Information Systems, 5(3), 53-69.

Lim, C. F. F. (2011). The relationship between usage of management accounting information and business performance: SMEs in Sabah, Malaysia (Doctoral dissertation, Universiti Malaysia Sabah).

Lybaert, N. (1998). The information use in a SME: Its importance and some elements of influence. Small Business Economics, 10(2), 171-191.

Maelah, R., Al Lami M. F. F., \& Ghassan, G. (2019). Management accounting information usefulness and cloud computing qualities among small-to-medium enterprises. International Journal of Management Studies, 26(1), 1-31.

Marand, A. A., Marand, E. A., \& Dashtebayaz, M. L. (2013). Investigating the effects of cloud computing on accounting and its comparison with traditional models. Advances in Environmental Biology, 7(10 S1), 2836-2847.

Marston, S., Li, Z., Bandyopadhyay, S., Zhang, J., \& Ghalsasi, A. (2011). Cloud computing - The business perspective. Decision Support Systems, 51(1), 176-189.

Mayr, A., Lengauer, V., \& Parasote, S. (2006). The impact of accounting information on management's: Wexiödisk - A case study (Bachelor's thesis, Vaxjo University).

Merigó, J. M., Gil-Lafuente, A. M. \& Gil-Lafuente, J. (2016). Business, industrial marketing and uncertainty. Journal of Business \& Industrial Marketing, 31(3), 325-327.

Mia, L., \& Chenhall, R. H. (1994). The usefulness of management accounting systems, functional differentiation and managerial effectiveness. Accounting, Organizations and Society, 19(1), 1-13. 
Mia, L., \& Patiar, A. (2001). The use of management accounting systems in hotels: An exploratory study. International Journal of Hospitality Management, 20(2), 111-128.

Mia, L., \& Winata, L. (2008). Manufacturing strategy, broad scope MAS information and information and communication technology. The British Accounting Review, 40(2), 182-192.

Mia, L., \& Winata, L. (2014). Manufacturing strategy and organisational performance: The role of competition and MAS information. Journal of Accounting \& Organizational Change, 10(1), 83-115.

Mitchell, F., \& Reid, G. C. (2000). Problems, challenges and opportunities: The small business as a setting for management accounting research. Management Accounting Research, 11(4), 385-390.

Mohammadi, S., Mohammadi, A., \& Mehmandoost, M. (2015). Check cloud computing profession in comparison with traditional brands. International Journal of Accounting and Economics Studies, 3(1), 29-35.

Mohammed, B. A. H., Maelah, R., \& Amir, A. M. (2019). Strategic management accounting information and performance of private hospitals in Malaysia. International Journal of Economics, Management and Accounting, 27, 473-502.

Moilanen, R. (2001). A learning organization: Machine or human? Finland: University of Jyväskylä.

Monteiro, L., \& Vasconcelos, A. (2013). Survey on important cloud service provider attributes using the SMI framework. Procedia Technology, 9, 253-259.

Moore, D. S., Notz, W. I, \& Flinger, M. A. (2013). The basic practice of statistics $\left(6^{\text {th }}\right.$ ed.). New York, NY: W. H. Freeman and Company.

Nandan, R. (2010). Management accounting needs of SMEs and the role of professional accountants: A renewed research agenda. Journal of Applied Management Accounting Research, 8(1), 65-78. 
Nguyen, H. Q., \& Le, O. T. T. (2020). Factors affecting the intention to apply management accounting in enterprises in Vietnam. Journal of Asian Finance, Economics and Business, 7(6), 95-107.

Nik Abdullah, N. H. (2020). Assessing strategic management accounting practices in public interest companies in Malaysia. Indonesian Journal of Economics, Social, and Humanities, 2(1), 13-25.

Nugroho, M. A., Susilo, A. Z., Fajar, M. A., \& Rahmawati, D. (2017). Exploratory study of SMEs technology adoption readiness factors. Procedia Computer Science, 124, 329-336.

Nuhu, N. A., Baird, K. \& Appuhami, R. (2016). The association between the use of management accounting practices with organizational change and organizational performance. Advances in Management Accounting, 26, 67-98.

Nuseibeh, H. (2011). Adoption of cloud computing in organizations. Paper presented at the AMCIS 2011.

Obeidat, M. A., \& Turgay, T. (2012). Empirical analysis for the factors affecting the adoption of cloud computing initiatives by information technology executives. Journal of Management Research, 5(1), 152178.

Odar, M., Kavčič, S., \& Jerman, M. (2015). The role of a management accounting system in the decision-making process: Evidence from a post-transition economy. Engineering Economics, 26(1), 84-92.

Omar, M. W., \& Ali, M. N. M. (2010). Brand loyalty and relationship marketing in Islamic banking system. Canadian Social Science, 6(1), 25-32.

Papadopoulos, T., Baltas, K. N., \& Balta, M. E. (2020). The use of digital technologies by small and medium enterprises during COVID-19: Implications for theory and practice. International Journal of Information Management, 55, 102192. 
Pierce, B., \& O'Dea, T. (2003). Management accounting information and the needs of managers: Perceptions of managers and accountants compared. The British Accounting Review, 35(3), 257-290.

Quinn, M., Strauss, E., \& Kristandl, G. (2014). The effects of cloud technology on management accounting and business decision-making. Financial Management, 10(6), 1-12.

Rahman, A. Z.A., Omar, N. H., \& Hoo, T. Y. (1997). A survey of management accounting practices in Malaysian manufacturing companies.

Raman, N., Yuserrie, Z., \& Michael, T. (2009). Strategic management accounting information elements: Malaysian evidence. Asia-Pacific Management Accounting Journal, 4(1), 17-34.

Ramli, I., \& Iskandar, D. (2014). Control authority, business strategy, and the characteristics of management accounting information systems. Procedia-Social and Behavioral Sciences, 164, 384-390.

Riemenschneider, C. K., Harrison, D. A., \& Mykytyn, P. P. (2003). Understanding IT adoption decisions in small business: Integrating current theories. Information \& Management, 40(4), 269-285.

Rockmann, R., Weeger, A., \& Gewald, H. (2014, June). Identifying organizational capabilities for the enterprise-Wide usage of cloud computing. Paper presented at the Pacific Asia Conference on Information Systems (PACIS).

Salmon, S., \& Joiner, T. (2006). Integrative management information, role ambiguity and managerial performance: An intervening model. Paper presented at the 20th Australia and New Zealand Academy of Management Conference.

Schäffer, U., \& Steiners, D. (2004). The use of management accounting information, learning and organizational performance. European Business School-Chair of Management Accounting \& Control, 1-34. 
Sherine, F., \& McLellan, J. D. (2017). A system of innovative management accounting practices for Egyptian manufacturers. Journal of Accounting, Ethics and Public Policy, 18(1), 23-57.

SME Corp. Malaysia (2013). Guideline for new SME definition - October 2013. Retrieved from https://www.smecorp.gov.my/images/pdf/ Guideline_for_New_SME_Definition_7Jan2014.pdf

Soobaroyen, T., \& Poorundersing, B. (2008). The effectiveness of management accounting systems: Evidence from functional managers in a developing country. Managerial Auditing Journal, 23(2), 187-219.

Straub, D., Boudreau, M.-C., \& Gefen, D. (2004). Validation guidelines for IS positivist research. Communications of the Association for Information Systems, 13(1), Article 24.

Sulaiman, M. b., Nazli Nik Ahmad, N., \& Alwi, N. (2004). Management accounting practices in selected Asian countries: A review of the literature. Managerial Auditing Journal, 19(4), 493-508.

Tarmidi, M., Rasid, S. Z. A., Alrazi, B., \& Roni, R. A. (2014). Cloud computing awareness and adoption among accounting practitioners in Malaysia. Procedia-Social and Behavioral Sciences, 164(1), 569-574.

Theriou, N., Maditinos, D., \& Šević, Ž. (2009, July). Management control systems and strategy: A Resource based Perspective. Evidence from Greece. Paper presented at the 7th International Conference on Accounting and Finance in transition-ICAFT.

Ting, O. (2004). SMEs in Malaysia: Pivot points for change. On line available at http://www. mca. org. my, 01-27.

Truong, D. (2010). How cloud computing enhances competitive advantages: A research model for small businesses. The Business Review, Cambridge, 15(1), 59-65.

Tsagklis, I. (2013). Advantages and disadvantages of cloud computing - Cloud computing pros and cons. Retrieved from https://www. javacodegeeks.com/2013/04/advantages-and-disadvant ages-of-cloudcomputing-cloud-computing-pros-and-cons.html. 